\title{
A comparative analysis of hot and cold flashless forging of a stepped shaft using vertically-parted dies
}

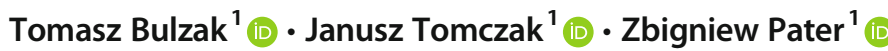

Received: 11 March 2021 / Accepted: 22 June 2021 / Published online: 10 July 2021

(C) The Author(s) 2021

\begin{abstract}
Flashless forging is classified as a precise metal forming technology. The main advantages of this technology are the reduction of the flash allowance and the shortening of the manufacturing time by eliminating the flash trimming operation. The article presents the process of one-step forging of a stepped shaft made of aluminum with the use of split dies. The process was carried out in cold and hot metal-forming conditions. The forging process was analyzed numerically using the Simufact Forming 15.0 software. The geometrical parameters of the obtained product were analyzed, and the distribution of effective strain, temperature, and the standardized cracking criterion was determined. The process force parameters were also determined. Numerical tests were verified in real conditions with the use of a specially designed device for forging in vertical split dies. Comparison of hot and cold forging in vertical split dies is presented. The comparative analysis results have demonstrated that the hot forging process has more advantages than the cold forging process. The hot forging process ensures higher accuracy of forged parts.
\end{abstract}

Keywords Flashless forging $\cdot$ Cold forging $\cdot$ Hot forging $\cdot$ Near net shape

\section{Introduction}

The shape and dimensions of precision forgings are largely similar to the shape and dimensions of finished parts. Precision forging is a near net-shape technology. It uses closed dies to prevent the formation of flash. The elimination of flash forming in the forging process reduces the consumption of material, energy (used for heating the billet in hot forging), and time (spent on flash trimming). In addition, flashless forging preserves the continuity of metal fibers, increasing in this way the strength of parts. Initially, flashless forging was used only to produce axisymmetric parts with simple shapes. Nowadays, however, the technology is increasingly used to produce flashless forgings with complex shapes. Song and Im [1], for example, present a technology of flashless forging of bevel gears for use in the automotive industry. The process they describe involves forging gears from AISI4130 steel

Tomasz Bulzak

t.bulzak@pollub.pl

1 Department of Computer Modelling and Metal Forming Technologies, Faculty of Mechanical Engineering, Lublin University of Technology, Nadbystrzycka Str. 36, 20-618 Lublin, Poland under cold working conditions. Song and $\operatorname{Im}$ [1] have shown that the initial dimensions of the billet have a significant impact on the forging operation, i.e., correct filling of the die cavity, the value of forces acting on the tools, and tool strength. Flashless forging of parts with complex shapes has also been discussed by Vazquez and Altan [2], who used the example of a connecting rod. They observed that flashless forging required strict control of the volume of the pre-form and that, in practice, a thin axial fin of flash might form between the moving parts of the forging tools. A research team from Hanover has proposed several concepts for forging precision parts for the automotive industry [3]. The authors from Hanover of the article focus mainly on solutions for precision forging of crankshafts. Studies [4-7] report information on an innovative process of extruding precision products in a device with a moving container. In this process, the material is extruded radially into a cavity which is expanded during the process owing to the use of the moving container, which moves in the direction opposite to the movement of the punch. The concepts of flashless forging reported in the literature require the use of specialized machines, consisting of several tools effected by a system of wedges, and dies locked with the use of a spring mechanism. The overview of the literature indicates that the main area of application of precision forgings is the automotive industry [8-10]. 
The technology of vertical split-die forging has been known for a long time now, but it has rarely been used in industry. This technology has been most widely applied in the production of plumbing fittings and parts. Currently, split dies are being replaced with special devices with two dies and a system of punches driven by lever systems. Forging presses of this type permit to forge tees, cross tees, and other fittings with pre-formed holes [11]. Vertical split dies can also be used to produce inner races of $\mathrm{CV}$ joints [12]. In the cold forging process, the greatest problem is posed by the low durability of the tools. The stock material must also be specially prepared to reduce its hardness; for this purpose it is subjected to spheroidizing annealing (softening). In order to minimize the forging forces, the material is also coated with phosphate or molybdenum disulfide. Split dies can also be used for forging aluminum in isothermal conditions [13] or for extruding machining tools, such as twist drill bits [14, 15].

The traditional hot and cold forging process is widely used in the industry. The hot and cold forging process in split dies has not been compared so far. The article compares cold and hot forging in vertical split dies. A comparative analysis was carried out on the example of forging a stepped shaft. The analysis was performed in order to acquire new knowledge about the forging process in vertical split dies. The decision to carry out this analysis was made on the basis of the wide interest in flashless forging technologies.

\section{Materials and methods}

\subsection{Design of a stepped shaft and forging tools}

Figure 1 shows the geometry of the die inserts used and the dimensions of the die cavity, whose shape corresponds to the shape of the stepped shaft which is the subject of this analysis. The total length of the forged shaft was $125 \mathrm{~mm}$. Two die inserts were used in the forging operation. The die inserts had a conical shape, with the generatrix inclined at an angle of $12^{\circ}$. The dies were guided in the device 's grooves by guide poles. The dies were opened using a hydraulic ejector with a lever system. The forging device was installed on a PYE 160 SS hydraulic press (Fig. 2).

\subsection{FE modeling and experimental testing conditions}

Split-die forging was simulated by finite element method (FEM) using Simufact Forming software. The experimental tests were carried out under cold and hot working conditions. The material for cold forging was modeled as an elastic-plastic body, and the material for hot forging was modeled as a rigidplastic body. The tools for both processes were modeled as rigid bodies. Billet was modelled by hex element with 8 nodes. Rheological model of AW-6060 aluminum assumed that the value of flow stress $\sigma_{F}$ depends on effective strain $\varepsilon$,
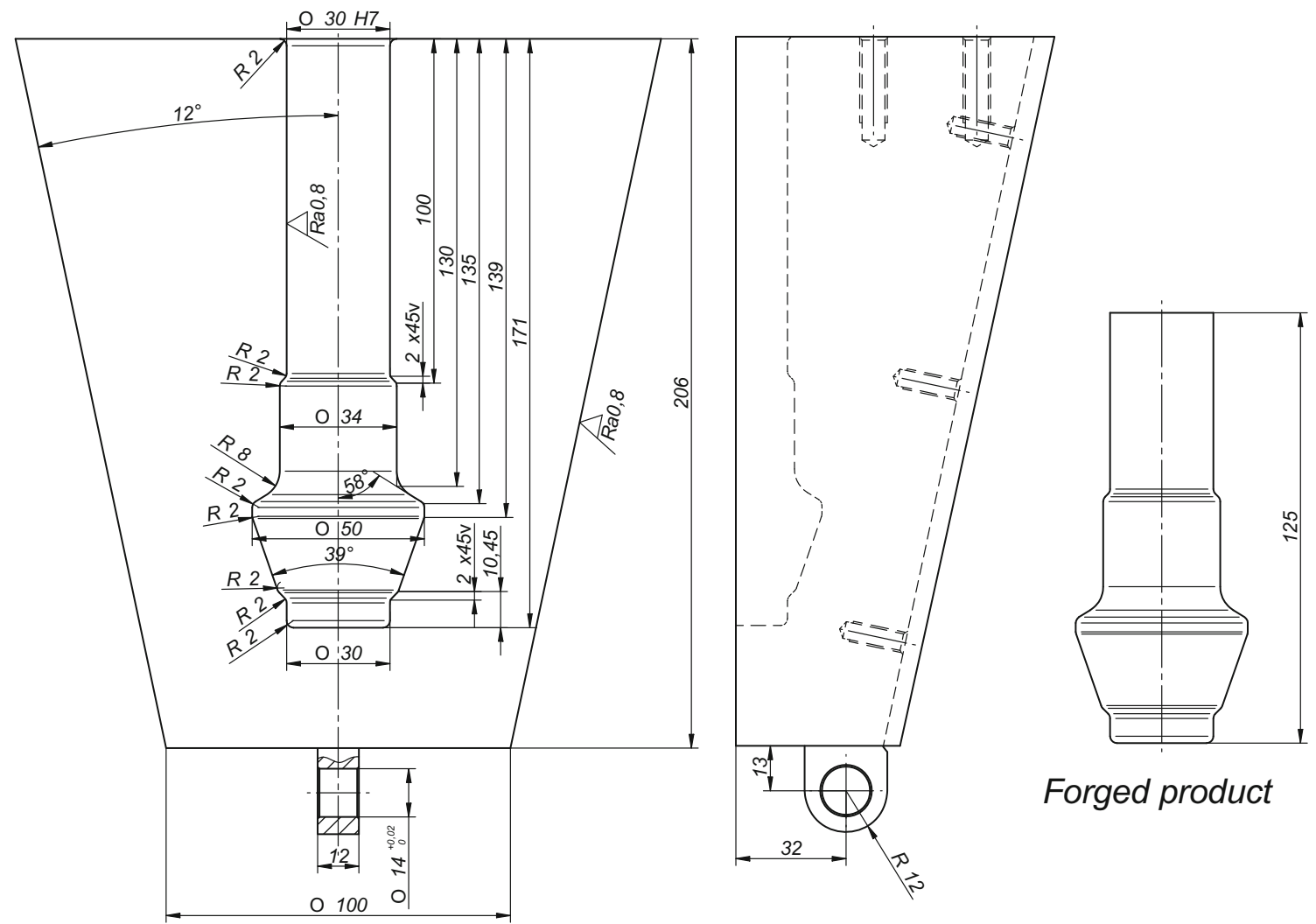

Forged product

Fig. 1 Vertical split die for forging a stepped shaft 
Fig. 2 A forging device with a vertical split die: (a) CAD model and (b) real view a)

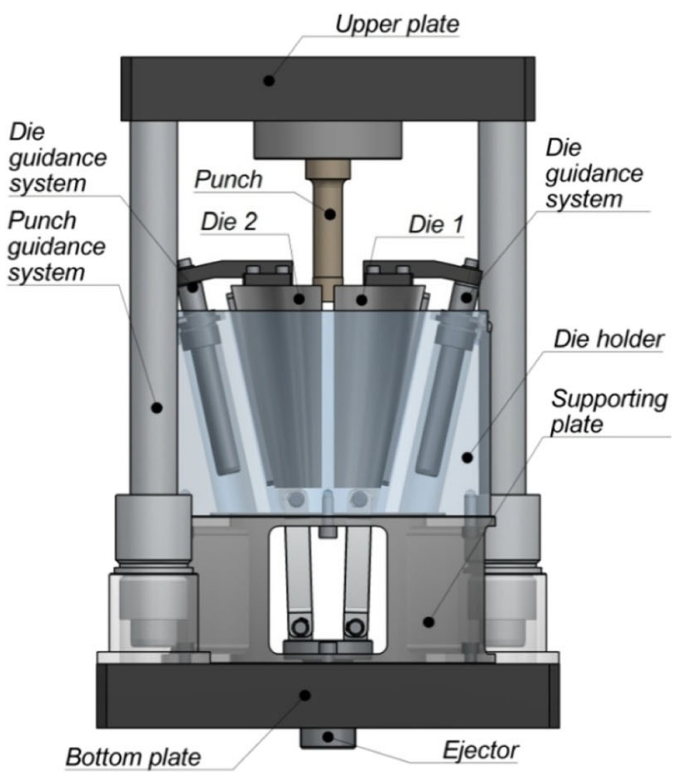

b)

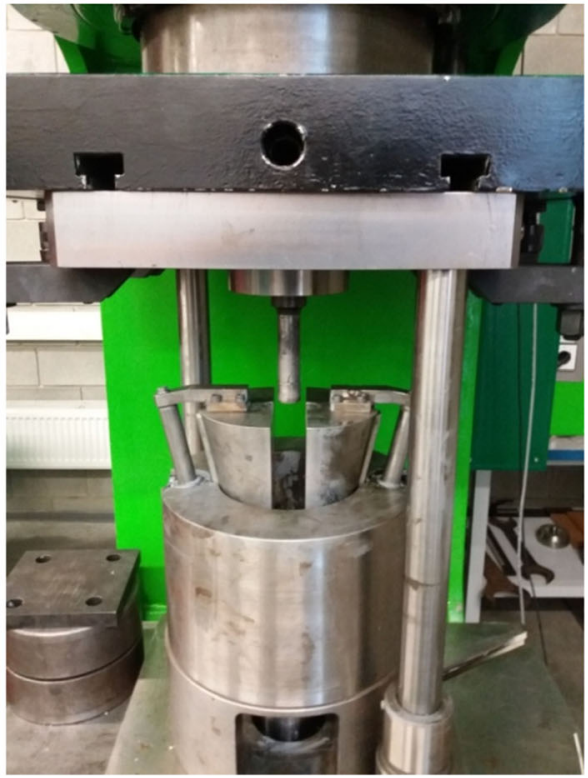

strain rate $\dot{\varepsilon}$, and temperature $T$. For the calculations, the von Mises yield criterion and the associated flow law were employed. It was assumed that $90 \%$ of the work of plastic deformation and friction is converted into heat. The value of the flow stress of AW-6060 aluminum resulted from the following equation:

$\sigma_{F}=196 e^{(-0.003394 T)} \varepsilon^{(-0.001072 T+0.3716)} e^{\left(\frac{-0.00011 T+0.0272}{\varepsilon}\right)} \varepsilon^{\cdot(0.00027 T-0.00643)}$,

where $\sigma_{F}$ is the flow stress [MPa], $\varepsilon$ is the effective strain, $\varepsilon$ is the strain rate $[1 / \mathrm{s}]$, and $T$ is the temperature $\left[{ }^{\circ} \mathrm{C}\right]$.Thermal parameters of AW-6060 aluminum are shown in Fig. 3.

The friction conditions were described by the constant friction model. The following friction factors were adopted: $m=$ 0.15 [16] for hot forging and $m=0.10$ for cold forging [17].

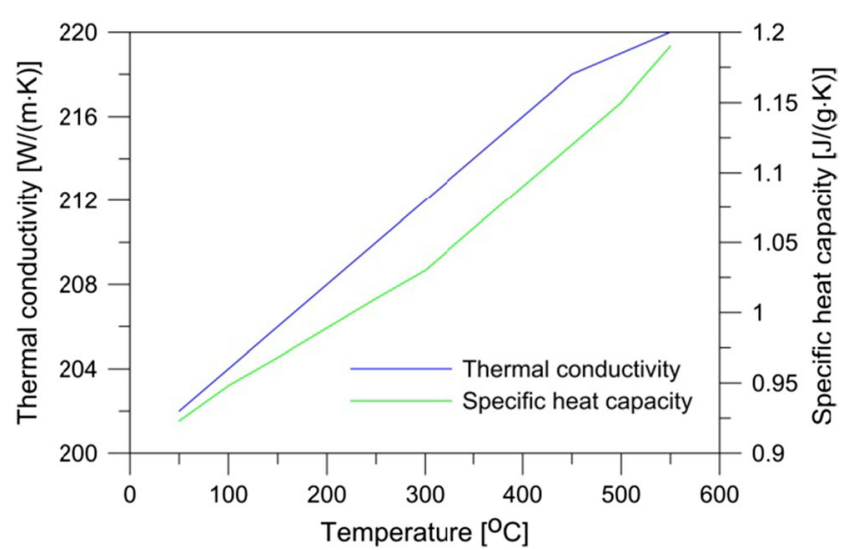

Fig. 3 Thermal parameters of AW-6060 aluminum used in FEM modeling
These friction factors corresponded to lubrication conditions in which a molybdenum disulfide lubricant and mineral oil were used for hot forging and cold forging, respectively. The thermal conditions were described by the billet-tool heat transfer coefficient $\left(8 \mathrm{~kW} / \mathrm{m}^{2} \mathrm{~K}\right)$ and the billet-environment heat transfer coefficient $\left(0.5 \mathrm{~kW} / \mathrm{m}^{2} \mathrm{~K}\right)$ [18]. During forging, the punch moved at a constant rate of $10 \mathrm{~mm} / \mathrm{s}$. The experimental tests were conducted using $\varnothing 30 \times 169 \mathrm{~mm}$ bars as stock material. The cold forging material was subjected to softening annealing at $415^{\circ} \mathrm{C}$ for $5 \mathrm{~h}$ before forging and cooled down to ambient temperature with the furnace. Hot forging was carried out at the initial billet temperature of $450{ }^{\circ} \mathrm{C}$.

\section{Results}

Figure 4 shows the distribution of effective strain on the surface and in the axial section of forged stepped shafts. No plastic strain is observed at the end journals of either shaft. This is due to the fact that the diameter of the billet is similar to the diameters of the end journals. In the case of the neck journal, increased strain is visible over its entire volume. In the hot forged shaft, the strains are uniformly distributed in this part of the shaft. In the cold forged shaft, inhomogeneous plastic strains are seen. Elevated plastic strain is also observed on the transition surface between two journals, which may be the result of the different nature of material flow in the cold and hot forging operations. In both cases, the largest strains are located in the conical step of the shaft in the area where the diameter increases the most during forging. The values of maximum strain are higher for hot forging compared with cold forging. 
Fig. 4 Distribution of effective strain in shaft after: (a) cold forging and (b) hot forging a)

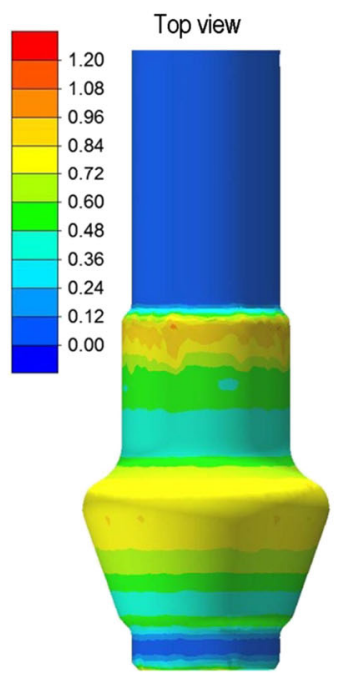

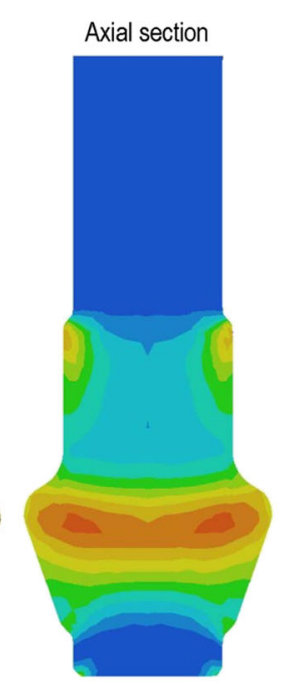

b)

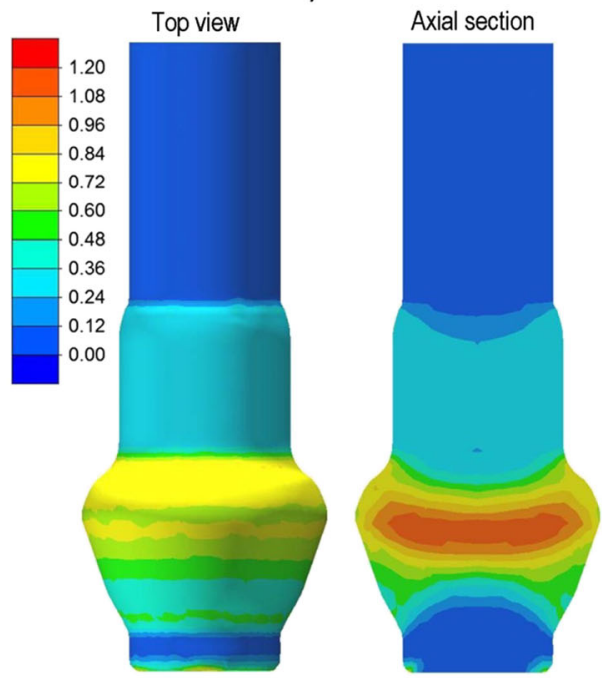

Figures 5 and 6 show the material flow patterns for the cold and hot forging operations, respectively. The material flow patterns are visualized using coordinate grids plotted on the axial plane passing through the axis of the forging. The material flows and fills in the die cavity differently during cold and hot forging. In both cases, the ends of the shaft have a diameter equal to the diameter of the billet. In the proposed forging method, the die cavity is filled by upsetting the billet. In the cold forging operation, at $25 \%$ completion, the material is upset evenly over the entire length. Half way into the process $(50 \%)$, the material fills the part of the die cavity with a diameter $\varnothing 34 \mathrm{~mm}$. In the second half of the process, the conical die cavity is being filled gradually. At the end of the operation ( $100 \%$ completion), the die cavity is completely filled with the material.

During hot forging, the material is upset in a different way than during cold forging. In the first quarter of the process, the course of upsetting is almost identical to that for cold forging. At $50 \%$ completion, however, a distinct barrel shape is formed in the conical area of the cavity. In the lower part of the cylindrical die cavity with a diameter $\varnothing 34 \mathrm{~mm}$, the material is in contact with the dies, but in the upper part, there is a gap between the billet and cavity walls. As the material is further upset, it fills the conical die cavity and the gap in the cylindrical part of the cavity is reduced. At $90 \%$ completion, the gap in the cylindrical portion of the die cavity is still not filled with material. It is only when the operation is fully completed $(100 \%)$ that the gap in the cylindrical part of the cavity is completely filled. However, at this stage, a gap is visible in the conical part of the die cavity.

The different patterns of material flow explain why areas of increased plastic strain develop in the upper portion (diameter $\varnothing 34 \mathrm{~mm}$ ) of the cylindrical part of the cold-forged shaft. During cold forging, this area is filled in the initial stage of the process, and so, later into the process, the material flows intensively in the radial and axial directions in the transition zone between the cavity parts with different diameters. During hot forging, the material flows mainly in the radial direction in the transition zone. As a consequence, during hot forging, the material does not rub against the die walls as intensively as it does during cold forging, which is reflected in the distribution of effective plastic strain (Fig. 4).
Fig. 5 Material flow pattern for the cold forging operation
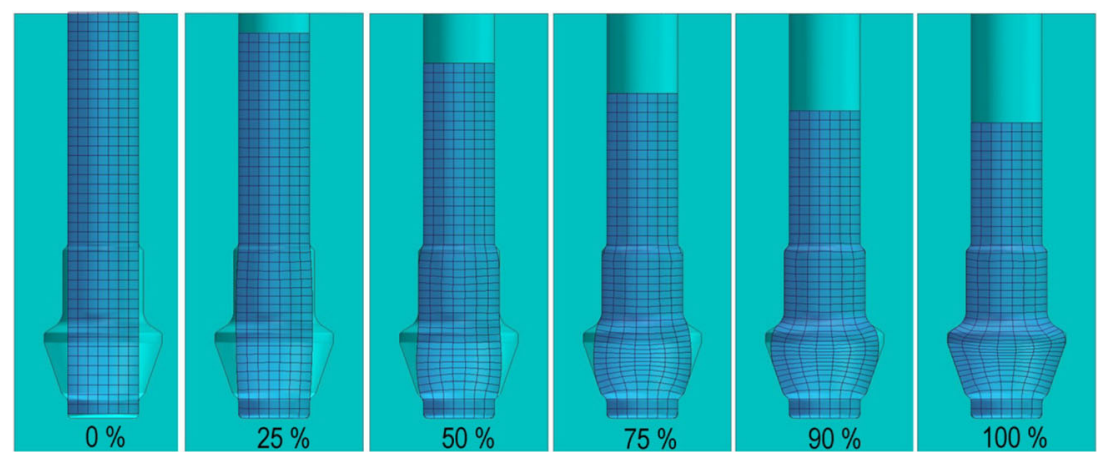
Fig. 6 Material flow pattern for the hot forging operation

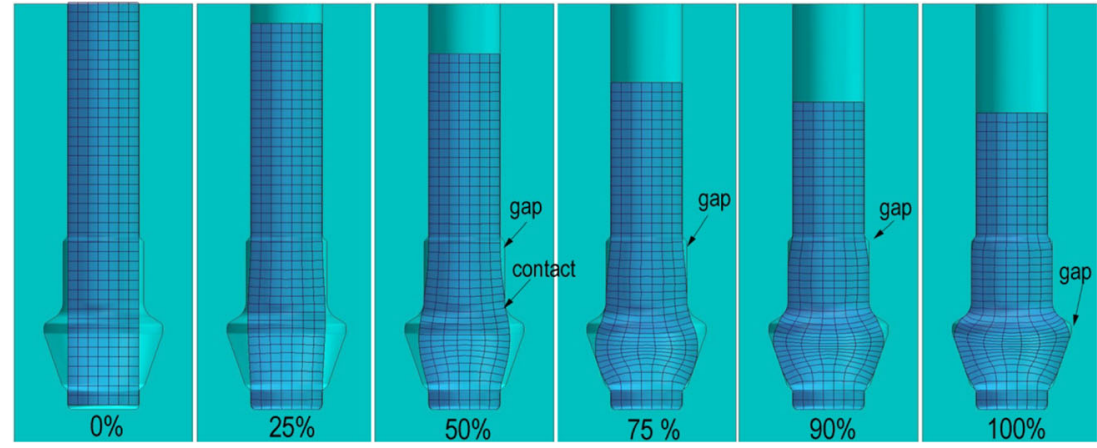

The fact that the material flow pattern is different during hot forging may be due to temperature changes. In the case of cold forging, the temperature changes are not so pronounced. Figure 7 compares the temperature distributions in a coldforged shaft and a hot-forged shaft. In the cold-forged part, a slight increase in temperature is observed in the area of the conical step of the shaft. The temperature increases as an effect of conversion of plastic work into heat. In the case of hot forging, the situation is quite different. In the initial stage of forging, at $25 \%$ completion, a clear drop in temperature from 241 to $199^{\circ} \mathrm{C}$ is observed in the area of contact with the punch. The material in the cylindrical part of the die cavity with a diameter $\varnothing 30 \mathrm{~mm}$ also cools down considerably to a temperature of about $300{ }^{\circ} \mathrm{C}$. In this situation, the material located in the bottom part of the die cavity has a higher plasticity than the cooled material in the top part of the cavity. Therefore, material which does not come into contact with the die is more susceptible to upsetting. Observations of temperature changes indicate that as the forging operation progresses, the material in the upper part of the die cavity cools down more intensively than the material in the lower part of the die cavity. The distribution of changes in the temperature of a forging shown in Fig. 7 explains the differences in material flow observed during hot and cold forging.

Figure 8 shows the distribution of mean stress at $90 \%$ completion of the forging operation. The results indicate that the dominant stresses in the split dies during shaft forging are compressive stresses. This type of stress state reduces the risk of loss of material cohesion and ensures the best plasticity of the material. In both forging operations, very low tensile stresses occurred on the circumference of the shaft step with the largest diameter. It is this area that showed the largest increase in diameter, which was accompanied by tensile stresses in the radial and circumferential directions. However, in both forging operations, tensile stresses were relatively low in relation to compressive stresses.

FEM software can be used to predict the formation of cracks in the material being deformed, on the basis of
Fig. 7 Temperature distribution $\left({ }^{\circ} \mathrm{C}\right)$ in shaft: (a) cold forging and (b) hot forging a)

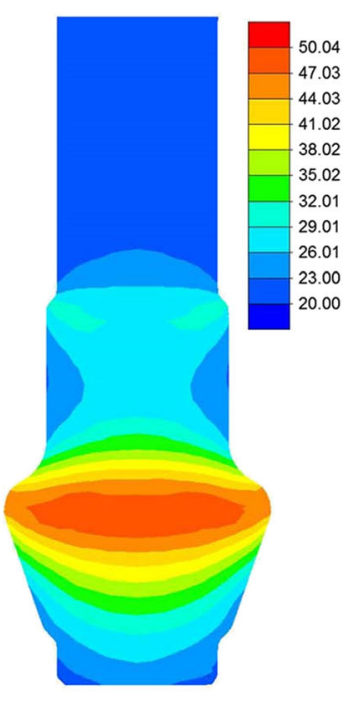

b)
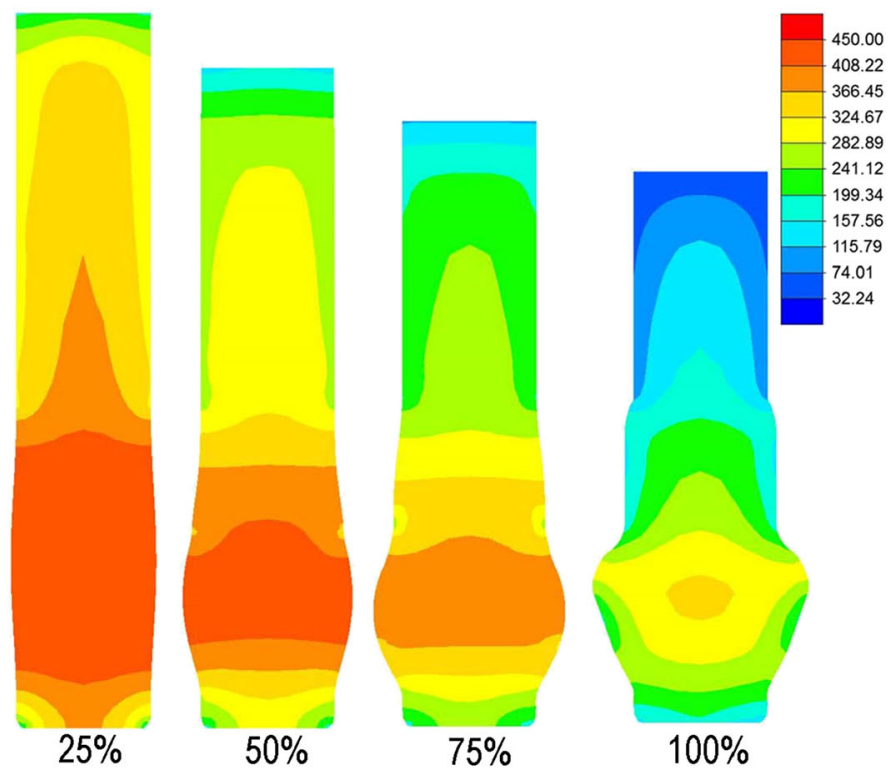
a)

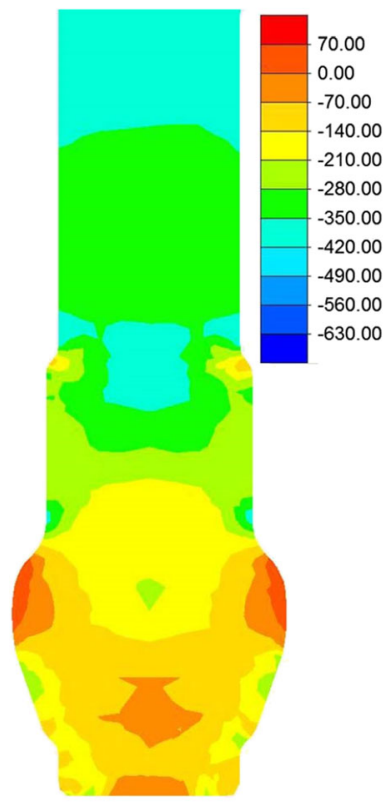

b)

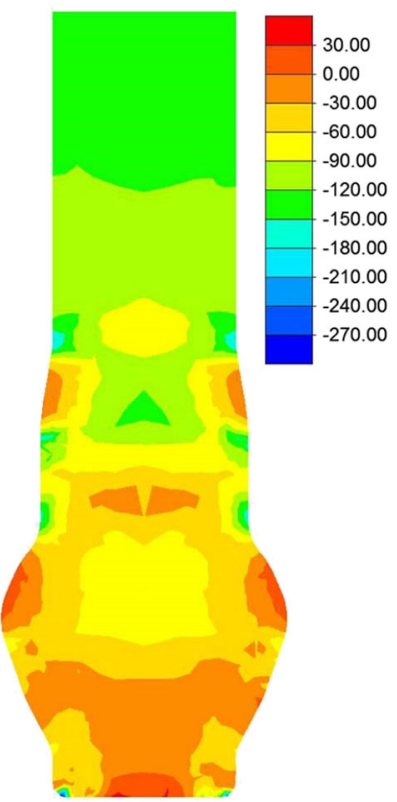

Fig. 8 Distribution of mean stress (MPa): (a) cold forging and (b) hot forging

empirical criteria. Fracture criteria are usually formalized as the integral of a function describing the impact of selected parameters on the course of a deformation process. A fracture criteria function depends mainly on the values of stress and strain. Figure 9 shows the distribution of the CockcroftLatham ductile fracture criterion. The distribution of the fracture criterion indicates that the material is most likely to crack in the area of the conical step of the shaft. The analysis of the stress distribution showed that tensile stresses occur in this area during forging. The results lead to the conclusion that

in the case of cold forging, the values of the CockcroftLatham criterion are only slightly higher than in the case of hot forging. The difference between the damage values is 0.03 . The area of occurrence of increased fracture criterion values on the conical part of the shaft is similar in both cases of forging.

Figure 10 shows the force characteristics of the analyzed forging operations. During the experimental tests, only the forging force exerted by the punch on the stock material was registered. Because we could not measure the radial force that tried to bring the dies apart during forging, we calculated it on the basis of FEM results. The maximum forging force recorded during cold forging was nearly twice as large as for hot forging. The maximum forging force was the same in experimental tests and FEM tests for both hot and cold forging. The maximum radial force recorded during cold forging was four times greater than the radial force exerted during hot forging. In the case of hot forging, the force curves obtained in the experimental and FEM tests are very similar. For cold forging, the calculated and experimental force curves are distinctly different. The force values observed in the cold forging experiments from the first second to the completion of the operation are decidedly higher than the FEM values. In the case of cold forging, the force gradually increased in an almost linear manner from the beginning of the operation. In the case of hot forging, the force in the initial stage of the operation reached a value of about $50 \mathrm{kN}$ and remained at this level $3.5 \mathrm{~s}$ into the process, to subsequently increase to the maximum value. When the forging force was constant during hot forging, the radial force was $0 \mathrm{kN}$. This means that the material did not exert pressure on the dies during the first $3.5 \mathrm{~s}$ of the operation. During this time, the material was pushed through the cylindrical part of the die cavity and upset in the lower part of the die and came into complete contact with the die walls at the end of the process.
Fig. 9 Distribution of the Cockcroft-Latham ductile fracture criterion: (a) cold forging and (b) hot forging a)

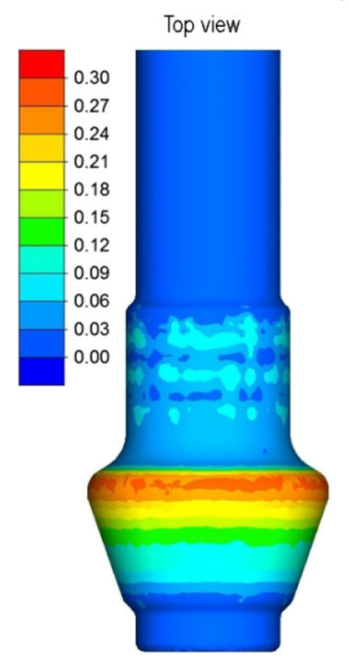

)

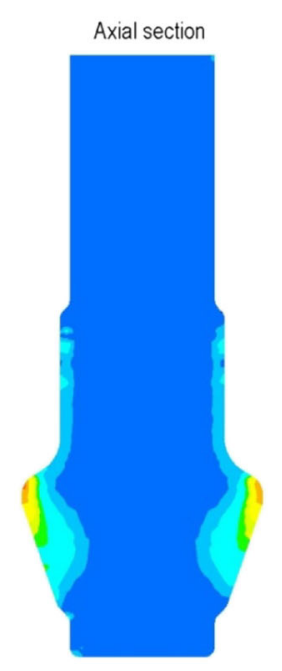

b)

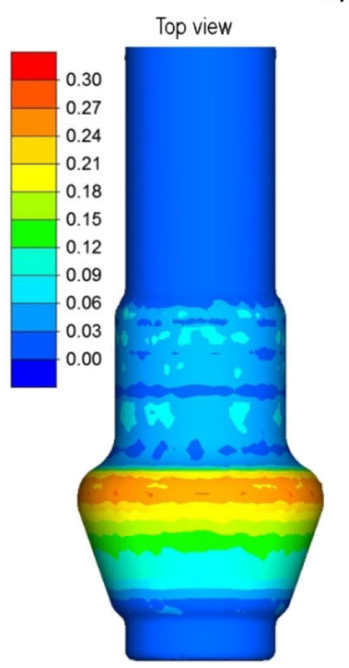

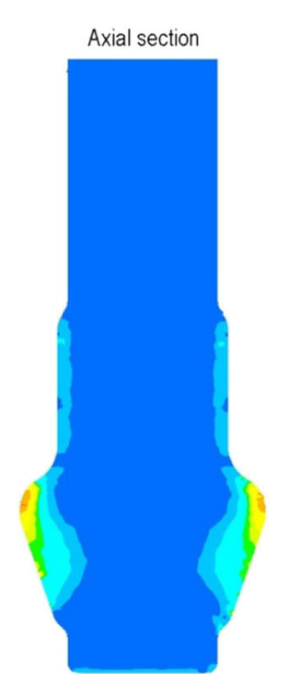


Fig. 10 Force curves of the forging process: (a) forging force and (b) radial force a)

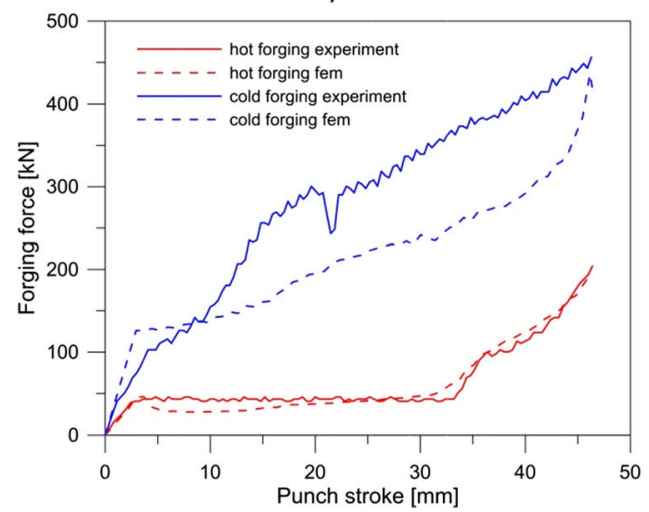

b)

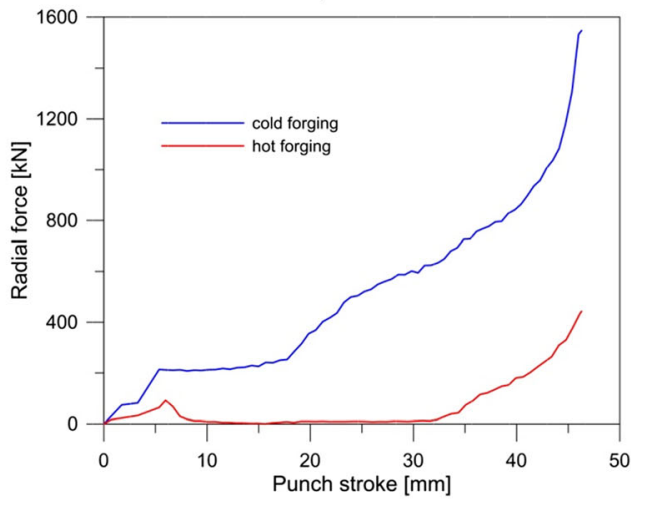

Table 1 compares the dimensions of the shaft obtained in the experiments and that designed in the CAD system. The hot-forged shaft has a much better dimensional accuracy. This is because the radial forces acting on the dies during forging were lower than in the cold-forging operation. The results indicate that the dies opened more widely under the influence of the radial force in the upper part of the die, which is confirmed by larger differences in dimensions $\varnothing \mathrm{A}$ and $\varnothing \mathrm{B}$ for both forging operations.

Figure 11 shows the forgings obtained in the experimental tests. In the cold forging operation, flash was formed in the parting plane. The parting of the dies caused backward flow of the material into the gap between the punch and the dies, producing axial flash in the upper part of the forging. The flash was formed along the parting line in the upper part of the forging on the shaft step with diameter $\varnothing \mathrm{A}$. In the case of the hot-forged part, only a trace of the parting line is visible on the surface. The surface of the upper step of the cold-forged part shows scratches and scuffing caused by the material rubbing against the surface of the die cavity (area B). In the cold forging operation, frictional forces acted powerfully on the material in the area of the die cavity with diameter $\varnothing \mathrm{A}$ almost throughout the entire process. The surface of the hotforged part does not have visible scratches or scuff marks. The flash formed during cold forging demonstrates that the forging force during experimental tests was higher than that obtained by FEM. Upon flowing into the gap between the dies, the material generated additional resistance forces, which were not observed in FEM, in which the tools were modelled as perfectly rigid bodies.

Figure 12 presents magnified areas $A$ and $B$ from Fig. 11 with small grooves located along the direction of material displacement during forging. In the case of area $\mathrm{B}$, the grooves are deeper and more visible. It can also be observed that scaling occurred in this area. The surface of the cold forged shaft is in a certainly worse condition. The condition of the shaft surface in the case of flashless forging depends on the value of spreading force occurring during forging. In the case of cold

Table 1 Dimensions of shafts after forging

\begin{tabular}{|c|c|c|c|c|}
\hline & $\varnothing \mathbf{A}, \mathbf{m m}$ & $\varnothing \mathbf{B}, \mathbf{m m}$ & $\varnothing \mathbf{C}, \mathbf{m m}$ & $\varnothing \mathbf{D}, \mathbf{m m}$ \\
\hline $\begin{array}{c}\text { CAD model } \\
\text { of a shaft }\end{array}$ & 30 & 34 & 50 & 30 \\
\hline $\begin{array}{c}\text { Hot-forged } \\
\text { shaft }\end{array}$ & 30.77 & 34.79 & 50.15 & 30.37 \\
\hline Difference & 0.77 & 0.79 & 0.15 & 0.37 \\
\hline $\begin{array}{c}\text { Cold-forged } \\
\text { shaft }\end{array}$ & 31.42 & 35.45 & 51.2 & 31.19 \\
\hline Difference & 1.42 & 1.45 & 1.2 & 1.19 \\
\hline
\end{tabular}




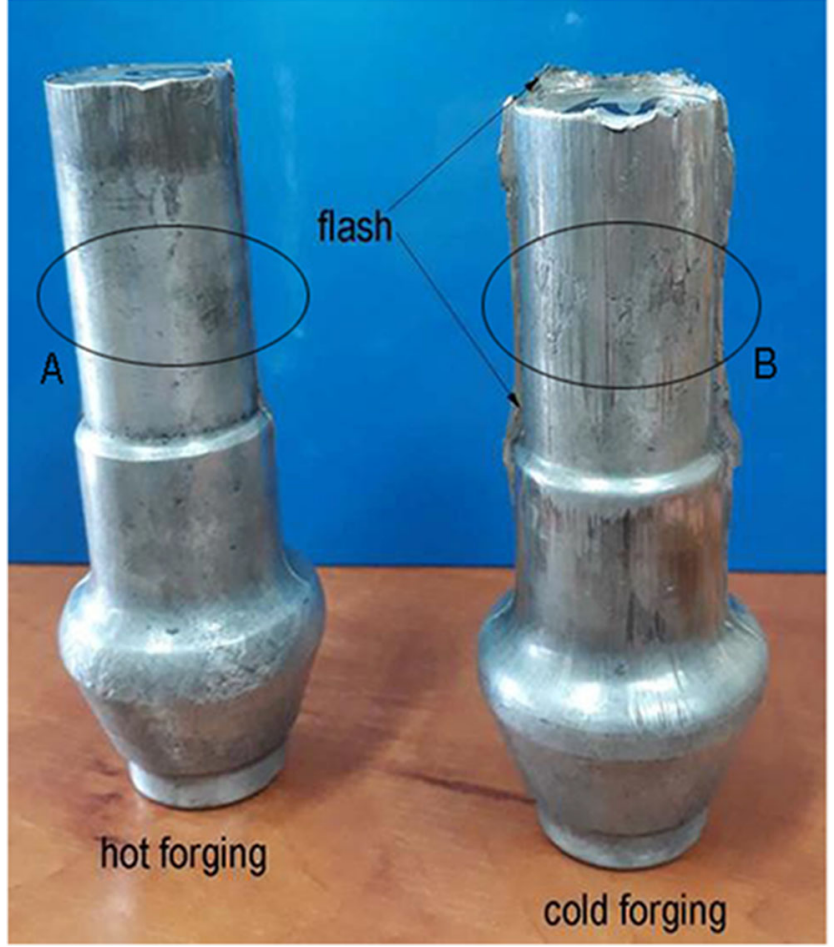

Fig. 11 Shaft forgings obtained in the experimental tests

forging, spreading force was significantly greater than in the case of hot forging. Due to this fact, more significant load between the dies and the formed material occurs in the case
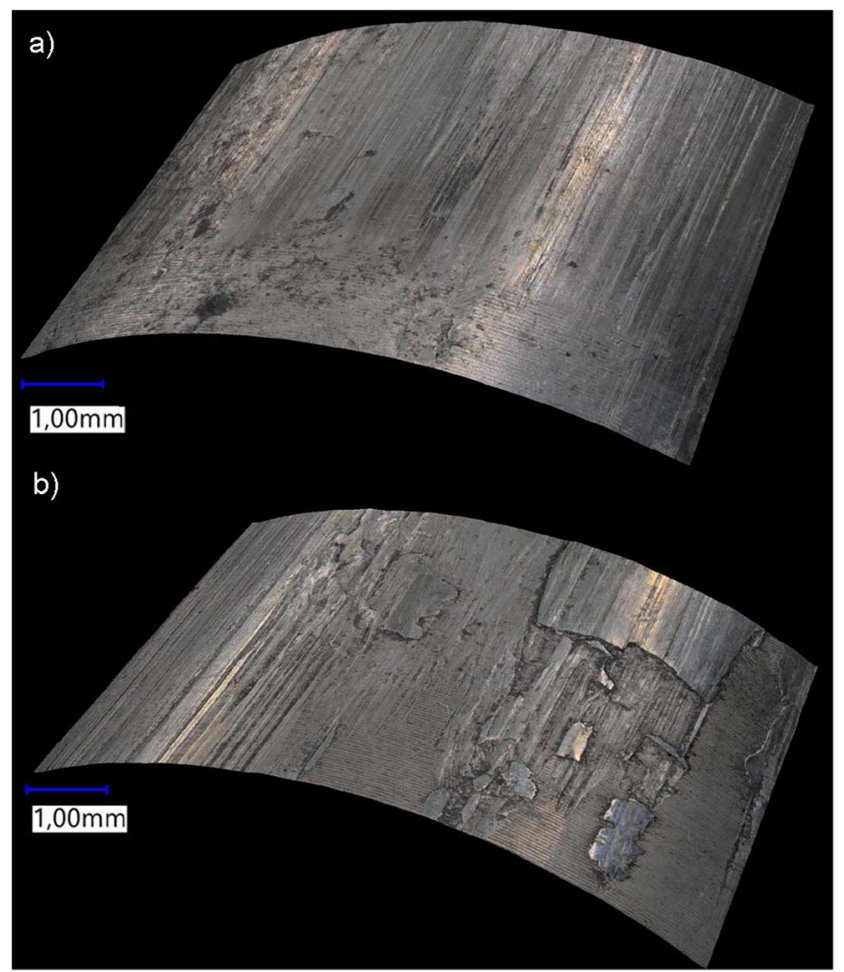

Fig. 12 Shaft surfaces magnified 20x: (a) the A area of the hot-forged shaft and (b) the B area of the cold-forged shaft of cold forging than during hot forging, which would cause material scaling. Figure 13 presents topography of the selected surfaces in $A$ and $B$ areas. An analysis of the topography shows that the grooves in the $B$ area of the cold forged shaft are deeper than in the case of hot forged shaft. The maximum difference in surface levels in the global scale for the analyzed $A$ area of the hot-forged shaft equals $125.68 \mu \mathrm{m}$. In the case of the $B$ area of the cold forged shaft the maximum surface levels in the global scale equals $485.16 \mu \mathrm{m}$. The topography of the surface of the hot forged shaft is more homogenous, which means that the local differences in topography are less significant.

Figure 14 presents the results of roughness measurement taken on the surface of the obtained shafts. The measurements were taken along the measurement sections marked on the shaft from Fig. 14. In the case of a cold forged shaft, a significant peak in value of roughness in the area where scaling and deep grooves occurred. The roughness value in this area for a cold forged shaft equals c.a. $60 \mu \mathrm{m}$, whereas for a hot forged shaft, it equals c.a. $15 \mu \mathrm{m}$. In the remaining areas of hot and cold forged shafts, such differences in the roughness value do not occur. The obtained roughness measurements indicate that hot forged shafts have a better surface, which is confirmed by the values of the Ra parameter measured throughout the length of the shaft.

\section{Conclusions}

The present study describes the processes of cold and hot flashless forging of a stepped shaft made of AW-6060 aluminum alloy. The tests confirm that this type of shaft can be forged in vertical split dies. The analysis of the results leads to the following conclusions and observations:

- In the proposed forging method, the material flow patterns observed during cold and hot forging are completely different. This stems from the differences in material workability in hot and cold forming. Moreover, in hot forging material workability changes due to cooling.

- The different flow patterns lead to differences in the distribution of plastic strains. As a result of different metal flow, the die impression in hot and cold forging is filled in a different way. In effect, the distributions of strain obtained in cold and hot forging differ. The location of the strain distribution differences depends on the differences in metal flow pattern in hot and cold forging.

- The risk of cracking is similar for hot and cold forging. The values and distributions of the normalized CockcroftLatham ductile fracture criterion are similar for both tested cases. This results from the fact that there are no significant differences in strains obtained for both tested cases. Additionally, the integrand of the employed fracture 
Fig. 13 Surface topography: (a) the A area of the hot-forged shaft and (b) the B area of the coldforged shaft

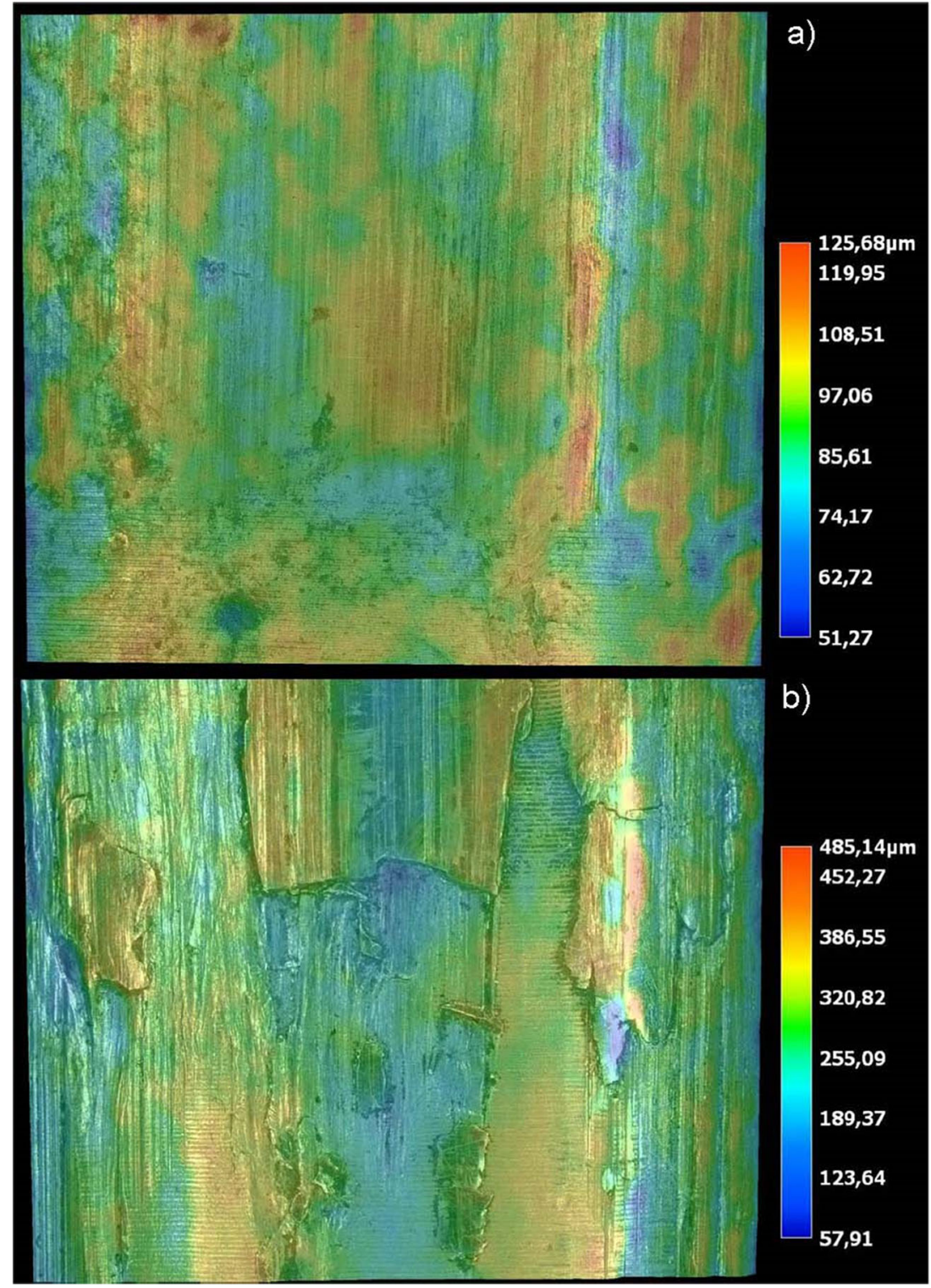

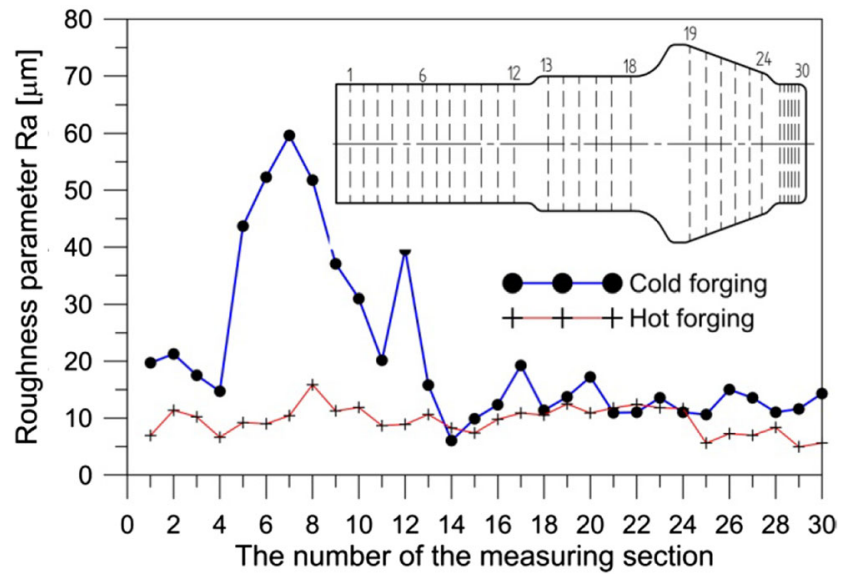

Fig. 14 Changes to the roughness parameter $\mathrm{Ra}$ criterion is expressed as a ratio of the maximum principal stress $\sigma_{1}$ to the reduced stress $\sigma_{i}$. When using the same forming pattern, the $\sigma_{1} / \sigma_{i}$ ratio does not depend on the process temperature

- The cold forging force is twice that of hot forging. The radial force observed during cold forging is four times greater than the radial force for hot forging.

- Cold forging creates a greater risk of the dies opening during the forging operation. This results from the occurrence of very high radial forces in cold forging, which leads to more extensive opening of the dies.

- Hot-forged parts have a better dimensional accuracy and surface quality. In hot forging the dies open to a smaller extent, which results in higher dimensional accuracy of forged parts. With the dies being tight, no flash is formed 
at the parting line. At higher radial forces, galling occurs on the surface of the workpiece.

- Considering all drawbacks and advantages of the tested cases of the forging process, it can be claimed that hot forging has more advantages than cold forging.

Acknowledgments The research was financed in the framework of the project Lublin University of Technology-Regional Excellence Initiative, funded by the Polish Ministry of Science and Higher Education (contract no. 030/RID/2018/19).

Authors' contributions T.B. and J.T. carried out the experiment. T.B. wrote the manuscript with support from Z.P. T.B. and Z.P. developed the theory and performed the FEM computations. T.B. and J.T. designed the device for forging test.

Funding The research was financed in the framework of the project Lublin University of Technology-Regional Excellence Initiative, funded by the Polish Ministry of Science and Higher Education (contract no. 030/ $\mathrm{RID} / 2018 / 19$ ).

Data availability The authors confirm that the data supporting the findings of this study are available within the article.

Code availability Not applicable.

\section{Declarations}

Conflict of interest None declared.

Ethics approval Not applicable.

Consent to participate Not applicable.

\section{Consent for publication Not applicable.}

Open Access This article is licensed under a Creative Commons Attribution 4.0 International License, which permits use, sharing, adaptation, distribution and reproduction in any medium or format, as long as you give appropriate credit to the original author(s) and the source, provide a link to the Creative Commons licence, and indicate if changes were made. The images or other third party material in this article are included in the article's Creative Commons licence, unless indicated otherwise in a credit line to the material. If material is not included in the article's Creative Commons licence and your intended use is not permitted by statutory regulation or exceeds the permitted use, you will need to obtain permission directly from the copyright holder. To view a copy of this licence, visit http://creativecommons.org/licenses/by/4.0/.

\section{References}

1. Song JH, Im YT (2007) Process design for closed-die forging of bevel gear by finite element analyses. J Mater Process Technol 192193:1-7. https://doi.org/10.1016/j.jmatprotec.2007.04.081
2. Vazquez V, Altan T (2000) Die design for flashless forging of complex parts. J Mater Process Technol 98:81-89. https://doi.org/ 10.1016/S0924-0136(99)00308-8

3. Behrens BA, Doege E, Reinsch S, Telkamp K, Daehndel H, Specker A (2007) Precision forging processes for high-duty automotive components. J Mater Process Technol 185:139-146. https:// doi.org/10.1016/j.jmatprotec.2006.03.132

4. Winiarski G, Gontarz A (2017) Numerical and experimental study of producing two-step flanges by extrusion with a movable sleeve. Arch Metall Mater 62:495-499. https://doi.org/10.1515/amm2017-0071

5. Winiarski G, Gontarz A, Samolyk G (2019) Flange formation in aluminium alloy EN AW 6060 tubes by radial extrusion with the use of a limit ring. Arch Metall Mater 19:1020-1028. https://doi. org/10.1016/j.acme.2019.05.006

6. Winiarski G, Bulzak T, Wojcik L, Szala M (2019) Effect of tool kinematics on tube flanging by extrusion with a moving sleeve. Adv Sci Technol Res J 13:210-216. https://doi.org/10.12913/ 22998624/110741

7. Winiarski G, Bulzak T, Wojcik L, Szala M (2020) Numerical analysis of a six stage forging process for producing hollow flanged parts from tubular blanks. Adv Sci Technol Res J 14:201-208. https://doi.org/10.12913/22998624/116748

8. Doege E, Bohnsack R (2000) Closed die technologies for hot forging. J Mater Process Technol 98:165-170. https://doi.org/10.1016/ S0924-0136(99)00194-6

9. Milutinović M, Vilotić D, Movrin D (2008) Precision forging - tool concepts and process design. J Technol Plast 33:73-89

10. Langner J, Stonis M, Behrens BA (2015) Innovative tool concepts and experimental trials of a flash reduced forging of crankshafts. Appl Mech Mater 736:158-164. https://doi.org/10.4028/www. scientific.net/AMM.736.158

11. Kchaou M, Elleuch R, Desplanques Y, Boidin X, Degallaix G (2010) Failure mechanisms of H13 die on relation to the forging process - A case study of brass gas valves. Eng Fail Anal 17:403415. https://doi.org/10.1016/j.engfailanal.2009.08.015

12. Ku TW, Kang BS (2014) Tool design for inner race cold forging with skew-type cross ball grooves. J Mater Process Technol 214: 1482-1502. https://doi.org/10.1016/j.jmatprotec.2014.02.021

13. Lin J, Kang F, Hu CK, Chen Q, Zhao Z (2014) Study of isothermal split-die precision forging process of high-strength aluminum alloy complex-shape forgings. Adv Mater Res 941-944:761-768. https:// doi.org/10.4028/www.scientific.net/AMR.941-944.1761

14. Bulzak T, Tomczak J, Pater Z, Majerski K (2019) Technological and construction aspects of the process of hot extrusion of twist drills. J Manuf Process 45:123-137. https://doi.org/10.1016/j. jmapro.2019.06.034

15. Bulzak T, Pater Z, Tomczak J (2017) New extrusion process for producing twist drills using split dies. Appl Comp Sci 13:55-63. https://doi.org/10.23743/acs-2017-21

16. Gontarz A, Dziubinska A, Okoń $€$ (2011) Determination of friction coefficients at elevated temperatures for some $\mathrm{Al}, \mathrm{Mg}$ and Ti alloys. Arch Metall Mater 52:379-384. https://doi.org/10.2478/v10172011-0040-x

17. Gariety M, Ngaile G (2005) Friction and Lubrication. In: Altan T, Ngaile G, Shen G (eds) Cold and hot forging. Fundamentals and Applications, vol 7, 1st edn. ASM International, Ohio, pp 67-81

18. Liu X, Ji K, Fakir OE, Fang H, Gharbi M, Wang LL (2017) Determination of the interfacial heat transfer coefficient for a hot aluminium stamping process. J Mater Process Technol 247:158117. https://doi.org/10.1016/j.jmatprotec.2017.04.005

Publisher's note Springer Nature remains neutral with regard to jurisdictional claims in published maps and institutional affiliations. 